\title{
Benign Orofacial Lesions in Libyan Population: A 17 Years Retrospective Study
}

\author{
Marwa Hatem ${ }^{1, *}$, Ziad S. Abdulmajid ${ }^{1}$, Elsanousi M. Taher ${ }^{1}$, Mohamed A. El Kabir ${ }^{2}$, \\ Mohamed A. Benrajab ${ }^{2}$ and Rafik Kwafi ${ }^{1}$
} ${ }^{I}$ Department of Oral Diagnosis, Oral Radiology and Oral and Maxillofacial Surgery, Libyan International Medical
University, Benghazi, Libya; ${ }^{2}$ Oral and Maxillofacial Surgery Unit, Tripoli Medical Centre, Tripoli, Libya

\begin{abstract}
Objectives: }}$ To analyze the frequency and type of benign orofacial lesions submitted for diagnosis at Tripoli Medical Centre over 17 years period (1997-2013). Materials and Methods: Entries for specimens from patients were retrieved and compiled into 9 diagnostic categories and 82 diagnoses. Results: During the 17 years period, a total of 975 specimens were evaluated, it comprised a male-female ratio of $0.76: 1$. The mean age of biopsied patients was $36.3 \pm 18.32$ years. The diagnostic category with the highest number of specimens was skin and mucosal pathology (22.87\%); and the most frequent diagnosis was pyogenic granuloma (14.05\%). Conclusion: Pyogenic granuloma, lichen planus, radicular cyst and fibroepithelial polyp were found to be the most predominant diagnoses. Frequencies of most benign orofacial diseases were comparable to similar studies in the literature and to those reported from the eastern region of Libya. Further surveys are needed to define the epidemiology of orofacial diseases in Libyan population.
\end{abstract}

Keywords: Benign, histopathological, Libya, orofacial, retrospective, specimens.

\section{INTRODUCTION}

Histopathological analysis is an important complementary tool that aids in the establishment of a definitive diagnosis. It is essential that dental practitioners have a perceived knowledge of the clinical and demographic characteristics associated with the occurrence of the versatile benign orofacial lesions, since many of them may exhibit similar clinical and/or radiographic characteristics to one another or may resemble malignant conditions.

Conducting an overall and detailed medical history and a comprehensive exploration of the oral cavity is essential to obtain a correct diagnosis. This influences the prognosis and the implementation of the appropriate treatment for each patient. Although occasionally it is possible to establish a clinical diagnosis, in most cases it is essential to conduct additional simple tests that provide valuable information, such as biopsies.

Biopsy is of paramount importance in the diagnostic process of oral lesions which, by clinical examination alone, can often be difficult and inaccurate [1]. Of particular importance is the contribution of biopsy and histopathology to the early detection of premalignant and malignant Lesions. Failure to biopsy may lead to persistence of a misdiagnosed malignant lesion or other serious pathology, resulting in an unfavourable downstream course for the patient and the attending clinician [2].

\footnotetext{
*Address correspondence to this author at the Department of Oral Diagnosis, Oral Radiology and Oral and Maxillofacial Surgery, Faculty of Dentistry, Libyan International Medical University, Benghazi, Libya; Tel: +962791755841; Fax: +218612233909;

E-mail: marwaaudey@yahoo.com
}

Most of the published epidemiological studies on orofacial lesions including those among Libyan population [3-6] are concerned with documenting the incidence or the prevalence of specific disease entity, such as dental caries, periodontal diseases or oral mucosal lesions. Furthermore, the majority of these investigations lack histological confirmation of diagnosis. Relatively few published surveys document the range of histologically diagnosed lesions over a given time frame. Among these, three studies from the United States with 400 specimen over one year [7], 4723 specimens over 20 years [8] and 15783 specimens over 18.5 years [9], one study from Spain with 562 specimen over 14 years [10], another from Singapore with 2057 specimen over 5 years [11] and the largest survey comprising 44007 specimens submitted over 30 years in the United Kingdom [12].

Moreover, there are few documentations of the occurrence of orofacial lesions in Africa and the Middle East. These include: a study of 818 benign oral masses among Jordanian population [13] which reported high frequencies of pleomorphic adenoma, pyogenic granuloma and fibroepithelial polyp, a survey of 385 biopsied jaw lesions in Kuwait [14] that reported high frequencies of radicular cyst, dentigerous cyst and keratocystic odontogenic tumor and a survey of 310 oral lesions in Yemen [15] that reported high frequencies of benign tumors and Qad-induced white lesions. In Libya, a study of 405 benign tumors revealed that keratocystic odontogenic tumors and ameloblastoma were the most predominant diagnoses [5].

The aim of this study was to determine the range and the demographic characteristics of benign orofacial lesions in 975 oral and maxillofacial pathology specimens, submitted for diagnosis at Tripoli Medical Centre over 17 years period (1997-2013). 


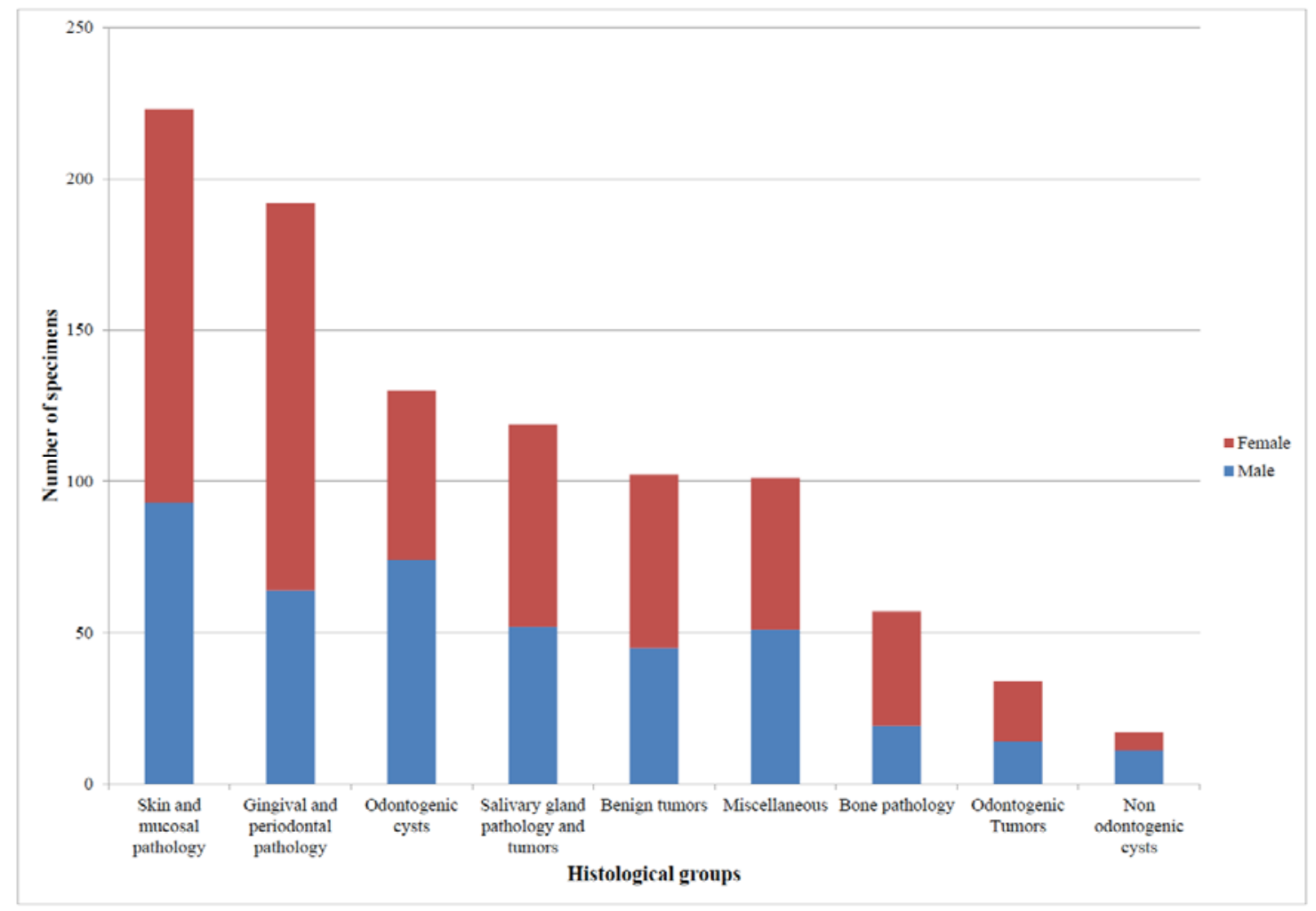

Fig. (1). Distribution of diagnoses according to histological grouping.

\section{MATERIALS AND METHODS}

This study was approved by Libyan International Medical University Ethical Committee and data acquisition was supervised by the head of oral and maxillofacial surgery unit at Tripoli Medical Centre.

Inclusion criteria were all histopathological reports of benign orofacial specimens referred to the oral and maxillofacial surgery unit at Tripoli Medical Centre between 1997 and 2013. Case files with missing patient information or inconclusive diagnoses were excluded from the study.

\section{Classification Criteria}

Specimens were compiled into 9 diagnostic categories according to their histological presentation as following: skin and mucosal pathology, gingival and periodontal pathology, odontogenic cysts, salivary gland pathology and tumors benign tumors, bone pathology, odontogenic tumors, non odontogenic cysts and miscellaneous. The miscellaneous group contained diseases that could not be placed into any other diagnostic category.

\section{Statistical Analysis}

Data were collected and prepared in Microsoft Excel spread-sheets 2013, and simple statistical procedures carried out (mean age, standard deviation, percentage, and charts). Patient confidentiality was maintained during the study.

\section{RESULTS}

During the 17 years period, a total of 1385 histopathological specimens were received from the oral and maxil- lofacial surgery unit at Tripoli Medical Centre, 83 cases were excluded due to incomplete data acquisition or unclear diagnosis. Of the remaining 1302 specimens, 975(74.88\%) were of benign conditions and $327(25.12 \%)$ were of malignant conditions. Fig. (1) shows the distribution of diagnoses according to their histological grouping.

Fig. (2) shows the distribution of age groups as related to gender. Of the 975 benign conditions, 423 were of males and 552 were of females (male: female ratio: 0.76:1). Age of biopsied patients ranged from 1 to 95 years (mean $36.3 \pm$ 18.32 years). The distribution of diagnoses according to histological grouping is shown in Table $\mathbf{1}$.

Overall, pyogenic granuloma was the most predominant diagnosis $(14.05 \%)$ followed by lichen planus $(6.66 \%)$ and radicular cysts $(5.84 \%)$. The most frequent pathology in each category was as following: skin and mucosal pathology: Lichen planus (65 specimens); gingival and periodontal pathology : pyogenic granuloma (137 specimens); odontogenic cysts: radicular cyst (57 specimens); salivary gland pathology and tumors: pleomorphic adenoma (45 specimens); benign tumors: fibroma (21 specimens); miscellaneous: benign non specific ulcer (42 specimens); bone pathology: central giant cell granuloma (17 specimens); odontogenic tumors: ameloblastoma (21 specimens); non odontogenic cysts: sebaceous cyst ( 5 specimens).

The 10 most frequent diagnoses are shown in Fig. (3); these comprised 578, nearly $60 \%$ of all specimens. Pyogenic granuloma was the most predominant diagnosis $(14.05 \%)$ followed by lichen planus $(6.66 \%)$ and radicular cysts $(5.84 \%)$. 


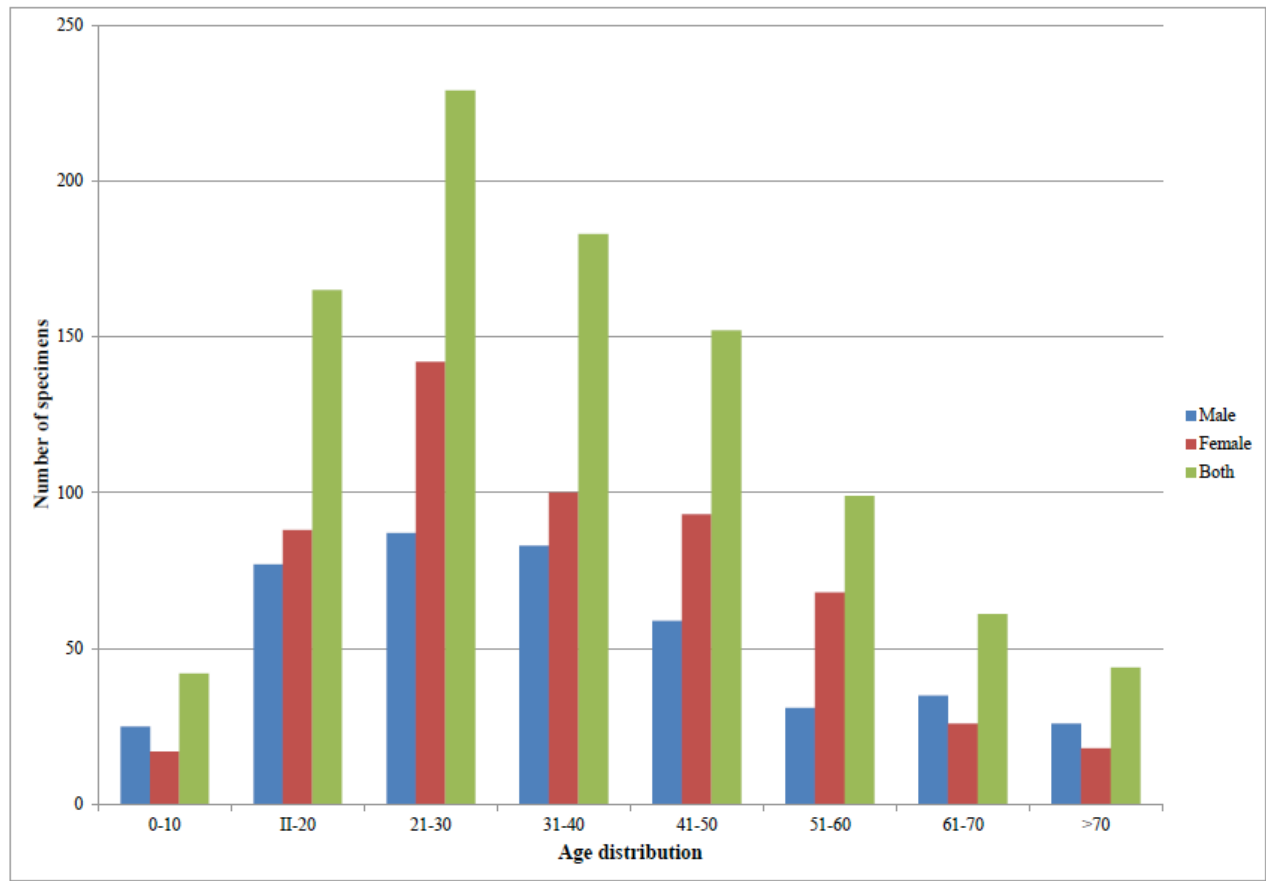

Fig. (2). The distribution of age groups as related to gender.

\section{DISCUSSION}

Most previous investigations concentrate on studying a single type of benign oral diseases or a group of closely related ones. This study investigates all benign oral lesions in a group of Libyans. Information obtained from similar surgical pathology reports are of great values to oral surgeons facing benign oral diseases on daily basis. Furthermore, results of such surveys may constitute a baseline for large-scale population based investigations.

Most published studies investigating the oral lesions are either limited to a specific disease entity like odontogenic cysts [3], tongue lesions [5], odontogenic tumors [4, 16-18] or salivary gland tumors [19]; or limited to a specific population group such as children [20] elderly [21] or military [22]. Therefore, direct comparisons with previous reports are difficult.

The number of benign orofacial specimens histologically analyzed at Tripoli Medical Centre over 17 years period accounted for $70.4 \%$ (975 specimens) of all submitted specimens. Overall, there was a slightly higher tendency for orofacial lesions to occur in females, with the male: female ratio at $0.76: 1$. This was also reported by Tay [11], Jones and Franklin [12] and Torres-Domingo et al. [23]. However, males were more commonly affected by certain conditions; these include odontogenic and non odontogenic cystic lesions.

\section{Skin and Mucosal Pathology}

This category contained the highest number of biopsied specimens. Lichen planus was ranked the most predominant diagnosis among the skin and mucosal lesions, and the second most frequently diagnosed pathology with $65(6.6 \%)$ specimens. Similar results were reported by Rossi and Hirsch [8], Tay [11], Jones and Franklin [12] and Cury et al.
[24]. However, Sixto-Requeijo reported substantially higher number of cases [10]. There was a higher tendency for this disease to occur in females as reported in previous studies $[12,23]$. This is probably due to the hormonal changes and stress among females [23]. Fibroepithelial polyp is believed to be a non specific focal hyperplasic reaction of the lamina propria in response to chronic irritation. In our study, it accounted for $5.84 \%$ of the total biopsies, which is significantly lower than reported by Jones and Franklin and others $[12,13]$. As reported in previous results [12, 13], fibroepithelial polyps were almost as twice in females as in males.

\section{Gingival and Periodontal Pathology}

Within this category, Pyogenic granuloma was the most predominant diagnosis and it amounted to $14.01 \%$ of the total. In most western studies, including those from United Kingdom [12], Singapore [11] and Brazil [25], it made up only $1.8-2.43 \%$ of the overall biopsies. However, our results were similar to biopsied tissues from Jordanian [13] and Yemeni populations [26]. The high female predilection for pyogenic granuloma may reflect the effect of estrogen and progesterone hormones in pregnancy on the pathogenesis of the condition, it was suggested that these hormones make the gingival tissue more susceptible to chronic inflammation caused by plaque and calculus [26]. In the present study, there was high frequency of pyogenic granuloma in females in child bearing age (mean age: 33.93 ).

\section{Cystic Lesions}

Both odontogenic and non odontogenic cysts were more prevalent among males. Radicular and dentigerous cysts were the most commonly diagnosed lesions in the odontogenic cysts category accounting for $49.17 \%$ and $41.37 \%$, respectively. These findings were also reported in other studies from Libya [1], Singapore [27] and Canada 
Table 1. Distribution of diagnoses according to the histological grouping.

\begin{tabular}{|c|c|c|c|c|c|}
\hline \multicolumn{6}{|l|}{ Skin and mucosal pathology } \\
\hline Fibroepithelial polyp & 57 & 19 & 38 & 38.4 & 25.65 \\
\hline Chronic non specific inflammation & 54 & 23 & 31 & 37.98 & 24.21 \\
\hline Pemphigus vulgaris & 8 & 2 & 6 & 45.87 & 3.58 \\
\hline Actinic keratosis & 5 & 4 & 1 & 68.8 & 2.24 \\
\hline Focal epithelial hyperplasia & 4 & 4 & 0 & 33.5 & 1.79 \\
\hline Compound nevus & 4 & 3 & 1 & 40 & 1.79 \\
\hline Solar elastosis & 2 & 0 & 2 & 60 & 0.89 \\
\hline Trichoepithelioma & 2 & 1 & 1 & 31 & 0.89 \\
\hline Lichenoid reaction & 2 & 1 & 1 & 28.5 & 0.89 \\
\hline Hydrocytoma & 1 & 0 & 1 & 63 & 0.44 \\
\hline Erythema multiforma & 1 & 0 & 1 & 26 & 0.44 \\
\hline Aphthous ulcer & 1 & 1 & 0 & 14 & 0.44 \\
\hline Total & 223 & 93 & 130 & & 100 \\
\hline \multicolumn{6}{|l|}{ Gingival and periodontal pathology } \\
\hline Inflammatory gingival hyperplasia & 6 & 3 & 3 & 31 & 3.15 \\
\hline Chronic gingivitis & 4 & 2 & 2 & 41.25 & 2.08 \\
\hline Peripheral ossifying fibroma & 4 & 0 & 4 & 33 & 2.08 \\
\hline Total & 192 & 64 & 128 & & 100 \\
\hline \multicolumn{6}{|l|}{ Odontogenic cysts } \\
\hline Diagnosis & Number & Male & Female & Mean Age & $\%$ of group \\
\hline Radicular cysts & 57 & 33 & 24 & 31.78 & 49.17 \\
\hline Dentigerous cysts & 48 & 27 & 21 & 30.09 & 41.37 \\
\hline Residual cysts & 6 & 6 & 0 & 24 & 5.17 \\
\hline Calcifying odontogenic cyst & 2 & 2 & 0 & 19 & 1.71 \\
\hline Lateral periodontal cyst & 1 & 0 & 1 & 30 & 0.87 \\
\hline Gingival cyst & 1 & 0 & 1 & 20 & 0.87 \\
\hline Glandular odontogenic cyst & 1 & 1 & 0 & 40 & 0.87 \\
\hline Total & 116 & 69 & 45 & & 100 \\
\hline
\end{tabular}


(Table 1) contd....

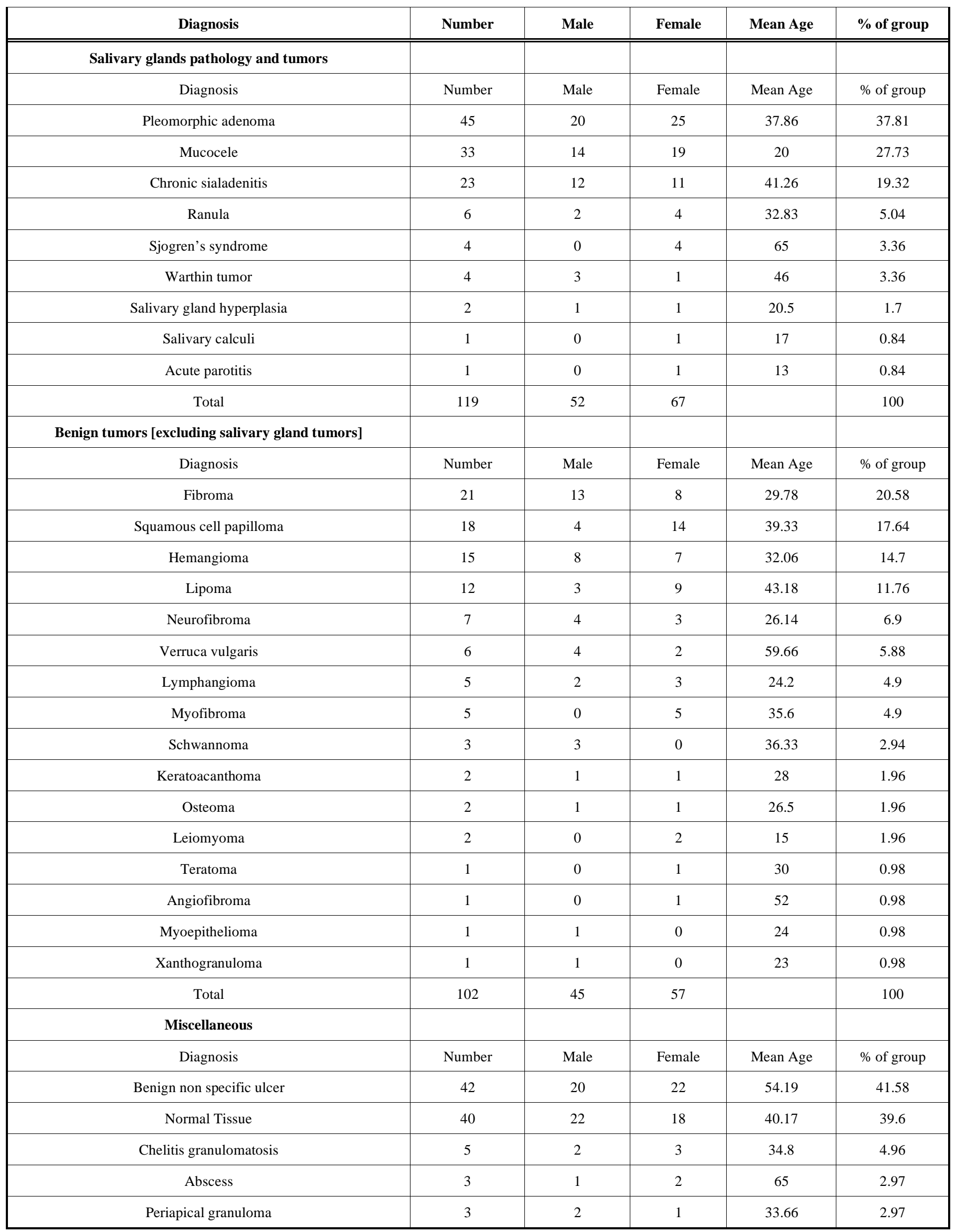


(Table 1) contd....

\begin{tabular}{|c|c|c|c|c|c|}
\hline Diagnosis & Number & Male & Female & Mean Age & $\%$ of group \\
\hline Tuberculosis & 2 & 0 & 2 & 47 & 1.98 \\
\hline Histiocytoma & 2 & 2 & 0 & 3 & 1.98 \\
\hline Total & 101 & 51 & 50 & & 100 \\
\hline \multicolumn{6}{|l|}{ Bone pathology } \\
\hline Diagnosis & Number & Male & Female & Mean Age & $\%$ of group \\
\hline Central giant cell granuloma & 17 & 4 & 13 & 35.62 & 29.31 \\
\hline Fibrous dysplasia & 11 & 3 & 8 & 20 & 18.97 \\
\hline Aneurysmal bone cyst & 1 & 1 & 0 & 23 & 1.72 \\
\hline Paget disease & 1 & 0 & 1 & 50 & 1.72 \\
\hline Total & 58 & 20 & 38 & & 100 \\
\hline \multicolumn{6}{|l|}{ Odontogenic tumors } \\
\hline Diagnosis & Number & Male & Female & Mean Age & $\%$ of group \\
\hline Ameloblastoma & 21 & 8 & 13 & 36.75 & 43.74 \\
\hline Odontogenic keratocysts & 14 & 5 & 9 & 28.57 & 29.15 \\
\hline Complex odontome & 1 & 0 & 1 & 47 & 2.1 \\
\hline Total & 48 & 19 & 29 & & 100 \\
\hline \multicolumn{6}{|l|}{ Non odontogenic cysts } \\
\hline Diagnosis & Number & Male & Female & Mean Age & $\%$ of group \\
\hline Sebaceous cyst & 5 & 4 & 1 & 41.6 & 31.25 \\
\hline Nasolabial cyst & 4 & 1 & 3 & 33 & 25 \\
\hline Epithelial inclusion cyst & 4 & 3 & 1 & 54.5 & 25 \\
\hline Nasopalatine cyst & 2 & 2 & 0 & 25.5 & 12.5 \\
\hline Branchial cyst & 1 & 0 & 1 & 21 & 6.25 \\
\hline Total & 16 & 10 & 6 & & 100 \\
\hline
\end{tabular}

[17]. Radicular cysts comprised $5.84 \%$ of all biopsied specimens, ranked the third most common diagnosis. It was ranked the forth most frequent diagnosis (5.3\%) in the United Kingdom [12].

Odontogenic keratocysts including parakeratinized and orthokeratinized types were reclassified as keratocystic odon- togenic tumors and jaw cysts with keratinisation according to the new WHO guidelines of 2005 [17]. Keratocystic odontogenic tumors comprised $1.43 \%$ of the total submitted specimens, this is substantially lower than the figures found in the United Kingdom [12], Mexico [28] and Germany [29] but similar to those reported in a previous study in Libyan population [30]. 


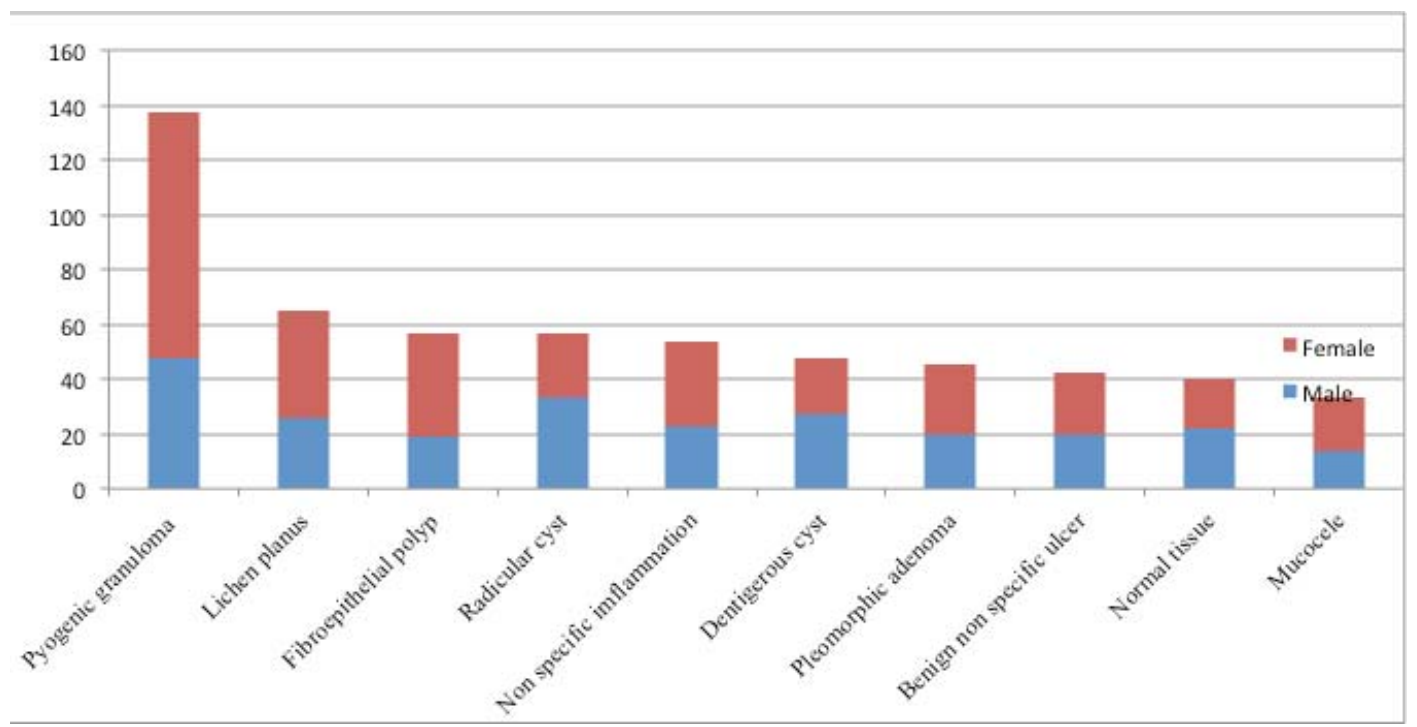

Fig. (3). The 10 most frequent diagnoses.

\section{Benign Tumors}

The ratio of benign to malignant tumors is approximately $0.3: 1$, Fibroma was the most frequent diagnosis in this category, supporting previous findings in the literature $[2,10,23$, 25]. In contrast, Jones and Franklin reported high occurrence of squamous cell papilloma and low proportions of fibromas [12]. The frequency of fibroma was higher in males, a result contrasting with previous studies $[2,25,21]$.

\section{Odontogenic Tumors}

Odontogenic tumors accounted for only $3.48 \%$ of all submitted specimens; which was similar to findings by Jones and Franklin [12], Delay [16], Bhaskar [31] and Regezi [32] and this tends to confirm that these lesions are rare. Bhaskar [32] reported a preponderance of odontogenic tumours at $2.37 \%$ of all submitted specimens, while Kim and Ellis [33] reported that of 847 cases referred to the Armed Forces Institute of Pathology; only 53.4\% (460 cases) were correctly identified as dental follicles and/or dental papillae; common misdiagnosis included odontogenic myxoma and other odontogenic tumours. The study by Kim and Ellis emphasized the importance of referral of such lesions to an oral and maxillofacial pathologist.

Our results showed that ameloblastoma was the most predominant odontogenic tumor, which is similar to that found by Tay [16] and Jones and Franklin [12] but differs from other studies. For example, ameloblastoma are more common in the African [17] and Chinese [18] whereas odontomas appear to be more common in Canada [16] and Mexico [28].

\section{Salivary Gland Pathology and Benign Tumors}

Mucocele, chronic sialadenitis and ranula were the most predominant diseases; similar results were reported by Jones and Franklin [12]. Mucocele made up 3.38\% of the total specimens, compared with $3.4 \%, 4.3 \%$ and $11.6 \%$ from other findings in the literature $[12,34]$, it was found to be the most frequent salivary gland lesion with predominance in children and young adults.
Benign tumors of salivary glands included pleomorphic adenoma and warthin tumor. Pleomorphic adenoma, a benign tumor of epithelial origin, made $4.6 \%$ of the total specimens. This was a relatively higher percentage than the figures reported by Jones and Franklin, and others [10, 21]. It was found to be the most predominant benign tumor in major and minor salivary glands $[10,12,21,35]$.

\section{Bone Pathology}

Central giant cell granuloma and ossifying fibroma were the most predominant diagnoses in this group, both of which showed female predilection. These results were similar to studies from eastern Libya [4] and Kuwait [14]. Other studies $[10,12]$ showed lower frequencies of these lesions and higher prevalence of other pathologies like osteoarthrosis, exostosis and BRONJ.

It has been demonstrated that factors such as smoking, alcohol consumption, socioeconomic status and prosthetic use can be associated with the occurrence of oral lesions [36]. Unfortunately, these factors are not often considered when histopathological evaluation is required. Since this information was not recorded in our laboratory reports, we were unable to evaluate its effect on the pathogenesis of benign oral lesion.

\section{CONCLUSION}

The number of investigated benign orofacial specimens reported at Tripoli Medical Centre over 17 years period was 975. Pyogenic granuloma, lichen planus, fibroepithelial polyp and radicular cyst were the most frequent diagnoses. The relative frequencies reported in our results were comparable to similar studies in the literature and to those reported from eastern part of Libya. These results can be used as a baseline for further nationwide population-based surveys of orofacial diseases in Libyan population.

\section{CONFLICT OF INTEREST}

The authors confirm that this article content has no conflict of interest. 


\section{ACKNOWLEDGEMENTS}

None declared.

\section{REFERENCES}

[1] Porter SR, Scully C. Early detection of oral cancer in the practice. Br Dent J 1998; 185: 72-3.

[2] Melrose RJ, Handlers JP, Kerpel S, Summerlin D, Tomich CJ. The use of biopsy in dental practice. The position of the American Academy of Oral and Maxillofacial Pathology. Gen Dent 2007; 55: 457-61.

[3] El-Gehani R, Krishnan B, Orafi H. The prevalence of inflammatory and developmental odontogenic cysts in a Libyan population. Libyan J Med 2008; 3: 75-7.

[4] El-Gehani R, Orafi M, Elarbi M, Subhashraj K. Benign tumours of orofacial region at Benghazi, Libya: A study of 405 cases. J Cranio Maxillofac Surg 2009; 37: 370-5.

[5] Byahatti SM, Ingafou MSH. The prevalence of tongue lesions in Libyan adult patients. J Clin Exp Dent 2010; 2: 163-8.

[6] Subhashraj K, Orafi M, Nair KV, El-Gehani R, Elarbi M. Primary malignant tumors of orofacial region at Benghazi, Libya: A 17 years review. J Cancer Epidemiol 2009; 33: 332-6.

[7] Greer RO Jr. Surgical oral pathology at the University Of Colorado School Of Dentistry: a survey of 400 cases. J Colo Dent Assoc 1976; 54: 13-6.

[8] Rossi EP, Hirsch SA. A survey of 4793 oral lesions with emphasis on neoplasia and premalignancy. J Am Dent Assoc 1977; 94: 8836.

[9] Weir JC, Davenport WD, Skinner RL. A diagnostic and epidemiologic survey of 15, 783 oral lesions. J Am Dent Assoc 1987; 115: 439-42.

[10] Sixto-Requeijo R, Diniz-Freitas M, Torreira-Lorenzo JC, GarcíaGarcía A, Gándara-Rey JM. An analysis of oral biopsies extracted from 1995 to 2009, in an oral medicine and surgery unit in Galicia [Spain]. Med Oral Patol Oral Cir Bucal 2012; 17: 16-22.

[11] Tay AB. A 5-year survey of oral biopsies in oral surgical unit in Singapore: 1993-1997. Ann Acad Med Singapore 1999; 28: 66571.

[12] Jones AV, Franklin CD. An analysis of oral and maxillofacial pathology found in adults over a 30-year period. J Oral Pathol Med 2006; 35: 392-401.

[13] Al-Khateeb TH. Benign oral masses in a northern jordanian population-a retrospective study. Open Dent J 2009; 3:147-53.

[14] Ali MA. Biopsied Jaw Lesions in Kuwait: a six-year retrospective analysis. Med Princ Pract 2011; 20: 550-5.

[15] Al-Maweri SA, Al-Jamaei AA, Al-Sufyani GA, Tarakji B, ShugaaAddin B. Oral mucosal lesions in elderly dental patients in Sana'a, Yemen. . J Int Soc Prev Community Dent 2015; 5(Suppl 1): S12-9.

[16] Daley TD, Wysocki GP, Pringle GA. Relative incidence of odontogenic tumors and oral and jaw cysts in a Canadian population. Oral Surg Oral Med Oral Pathol 1994; 77: 276-80.

[17] Lu Y, Xuan M, Takata T, et al. Odontogenic tumours: a dermographic study of 759 cases in a Chinese population. Oral Surg Oral Med Oral Pathol Oral Radiol Endod 1998; 86: 707-14.
[18] Ladeinde AL, Ajayi OF, Ogunlewe MO, et al. Odontogenic tumours: a review of 319 cases in a Nigerian teaching hospital. Oral Surg Oral Med Oral Pathol Oral Radiol Endod 2005; 99: 191-5.

[19] Pinkston JA, Cole P. Incidence rates of salivary gland tumours: results from a population-based study. Otolaryngol Head Neck Surg 1999; 120: 834-40.

[20] Jones AV, Franklin CD. An analysis of oral and maxillofacial pathology found in children over a 30 year period. Int $\mathrm{J}$ Paediatr Dent 2006; 16: 19-30.

[21] Corrêa L, Frigerio ML, Sousa SC, Novelli MD. Oral lesions in elderly population: a biopsy survey using 2250 histopathological records. Gerodontology 2006; 23: 48-54.

[22] James AC. Surgical oral pathology in a military hospital: a survey of 1,345 cases. Mil Med 1975; 140: 182-4.

[23] Torres-Domingo S, Bagan JV, Jiménez Y, et al. Benign tumors of the oral mucosa: A study of 300 patients. Med Oral Patol Oral Cir Bucal 2008; 13: 161-6.

[24] Cury PR, Porto LP, dos Santos JN, et al. Oral mucosal lesions in Indians from Northeast Brazil: cross-sectional study of prevalence and risk indicators. Medicine (Baltimore) 2014; 93: e140.

[25] Mendez M, Carrard VC, Haas AN, et al. A 10-year study of specimens submitted to oral pathology laboratory analysis: lesion occurrence and demographic features. Braz Oral Res 2012; 26: 235-41.

[26] Daley TD, Wysocki G, Wysocki P, Wysocki D. The major epulides: Clinicopathological correlations. J Can Dent Assoc 1990; 56: 627-30.

[27] Barnes L, Eveson JW, Reichart P, Sidransky D. World Health Organization classification of tumours: pathology and genetics of head and neck tumours. Lyon: IARC Press 2005.

[28] Mosqueda-Taylor A, Ledesma-Montes C, Caballero- Sandoval S, Portilla- Robertson J, Ruiz-Godoy Rivera LM, Meneses-Garcia A. Odontogenic tumors in Mexico: a collaborative retrospective study of 349 cases. Oral Sur Oral Med Oral Pathol Oral Radiol Endod 1997; 84: 672-5.

[29] Kreidler JF, Raubenheimer EJ, van Heerden WF. A retrospective analysis of 367 cystic lesions of the jaw: the Ulm experience. J Craniomaxillofac Surg 1993; 21: 339-41.

[30] Kamulegeya A, Kalyanyama BM. Oral maxillofacial neoplasms in an East African population a 10 year retrospective study of 1863 cases using histopathological reports. BMC Oral Health 2008; 8: 19.

[31] Bhaskar SN. Oral lesions in the aged population. A survey of 785 cases. Geriatrics 1968; 23: 137-4.

[32] Bhaskar SN. Oral pathology in the dental office: survey of 20,575 biopsy specimens. J Am Dent Assoc 1968; 76: 761-6.

[33] Regezi JA, Kerr DA, Courtney RM. Odomtogenic tumors: analysis of 706 cases. J Oral Surg 1978; 36: 771-8.

[34] Das S, Das AK. A review of paediatric oral biopsies from a surgical pathology service in a dental school. Pediatr Dent 1993; 15: 208-11.

[35] Jaber MA. Intraoral minor salivary gland tumors: a review of 75 cases in a Libyan population. Int J Oral Maxillofac Surg 2006; 35: 150-4.

[36] Carrard VC, Haas AN, Rados PV, et al. Prevalence and risk indicators of oral mucosal lesions in an urban population from South Brazil. Oral Dis 2011; 17: 171-9.

Received: December 30, 2014

Revised: September 21, 2015

Accepted: September 29, 2015

(C) Hatem et al.; Licensee Bentham Open.

This is an open access article licensed under the terms of the (https://creativecommons.org/licenses/by/4.0/legalcode), which permits unrestricted, noncommercial use, distribution and reproduction in any medium, provided the work is properly cited. 